\title{
The evolving role of surgery in the international public health agenda
}

\author{
O papel crescente da cirurgia na agenda \\ internacional de saúde pública
}

\section{La evolución del papel de la cirugía en la agenda internacional de salud pública}

Isabelle Citron 1

John G. Meara 1,2

doi: 10.1590/0102-311X00124217
In 2015, the entry of surgery into the public health agenda was marked by three key events. Firstly, the first volume of Disease Control Priorities- 31 was published by the World Bank - an entire volume devoted to surgery -, showing that despite significant variation in surgical care quality, tackling surgery could be amongst the most cost-effective public health measures to improve the population's health. Secondly, the Lancet Commission on Global Surgery was published, a document compiled by over 500 collaborators in 110 countries, detailing five key messages regarding the current state of surgery provision worldwide (Table 1), six surgical indicators meant to be collected by all countries, as well as a roadmap to improve access by 2030 2. Finally, the World Health Assembly (WHA) passed Resolution 68.15, which for the first time included emergency and essential surgical care as part of the universal health coverage (UHC) 3 .

Since then, an international global surgery community has assembled to transform these recommendations into action and to continue to advocate for the role of surgery as a public health priority internationally. As outlined in an article by Scheffer et al. 4, Brazil is taking steps to understand regional variations in provision of surgical services and workforce. Two of the major barriers for accessing surgery worldwide are the cost of care and difficulties concerning the navigation of the complexities of having multiple payers and providers.

\section{Table 1}

1 Program in Global Surgery and Social Change, Harvard Medical School, Boston, U.S.A.

2 Boston Children's Hospital, Boston, U.S.A.

\section{Correspondence}

I. Citron

Program in Global Surgery and Social Change, Harvard Medical School.

641 Huntington Ave, Boston, MA 02115, U.S.A.

isabelle.citron@gmail.com

Five key messages from the Lancet Commission on Global Surgery 2.

\begin{tabular}{cr}
\hline Key & Message \\
\hline 1 & 5 billion people lack access to safe, affordable surgical and anesthesia care when needed \\
2 & 143 million additional procedures are needed yearly to fill unmet need for surgery \\
3 & 33 million people face catastrophic expenses after surgical care yearly \\
4 & Investment in surgical and anesthesia care saves lives, is affordable, and promotes economic growth \\
5 & Surgery is an indivisible and indispensable part of health care \\
\hline
\end{tabular}


Brazil, where SUS is a single universal provider of free healthcare services, provides a unique setting to study surgical care provision and remaining barriers when these two important barriers are mitigated. In this case, subnational quality of care variations, efficiency of provision, and the interplay between the public and private sector rise to the top of the agenda. These provide interesting lessons to countries looking at the Brazilian model as a way to implement UHC and, by doing so, implement WHA Resolution 68.15, universal coverage of emergency and essential surgical care.

Alongside Brazil's efforts, many other countries have begun to improve access to surgical care through research, advocacy, and implementation initiatives. Only with a loud and unified voice can the surgical community, through research and advocacy, help maintain surgery as a permanent feature on the public agenda, recognized as an integral part of any resource allocation program.

To this end, meetings and plenary sessions on global surgery have happened yearly on the WHA, UN General Assembly, as well as in many national and international congresses such as the Brazilian College of Surgeons and the Latin American Congress on General Surgery. In addition, regional collaborations have emerged to advocate and share lessons learnt. For example, a meeting in São Paulo in December 2016 gathered leaders in surgery from eight Latin American countries to discuss how to implement improvements in the surgical care system across the region. Similarly, in Australasia, a regional collaboration across 13 countries has come together to benchmark surgical results. In recognition of the need to collaborate regionally and internationally to share data and best practices, the six indicators put forward by the Lancet Commission on Global Surgery have been accepted by the World Bank as part of the World Development Indicators and dedicated teams are already devoting time to collect these data annually (http://data.worldbank.org/indicator, accessed on 18/Jul/2017).

To translate advocacy and research into improvement for providers and patients, coordinated and sustainable implementation is required. One of the major recommendations of the Lancet Commission on Global Surgery was that countries begin a process of national surgical planning. In recognition of the complexity and multiple stakeholders involved in the provision of high quality care, it was suggested that the plan should include simultaneous action to strengthen five domains of service: delivery, infrastructure, human resources, information management, and financing.

Multiple countries have begun the process of national surgical, obstetric, and anesthesia planning. In 2017, Zambia was the first country to inaugurate a national surgical, obstetric, and anesthesia plan, a fully costed document outlining implementation measures ranging from trauma teaching, blood provision, construction of new operating theaters, and expansion of surgical and anesthesia residency training 5. Ethiopia has begun to implement its national surgical plan named Saving Lives Through Surgery (SaLTS) 6. To date, there has been implementation of national leadership training around surgery, widespread national investment in operating theatre infrastructure and equipment, training programs aimed at biomedical engineers, and programs to tackle surgical site infection, among others. Other countries such as Rwanda and Tanzania are also in the process of drafting national surgical plans.

Surgical care is an integral component of any properly functioning healthcare system. Globally, over 330 million procedures are performed each year, however, only $6.3 \%$ of surgical procedures are performed in low income countries. There is a large need and potential to collaborate with multiple stakeholders, including industry ${ }^{7}$. The first industry partner to take this opportunity was the General Electric Foundation (GEF) through a USD 25 million pledge to support SafeSurgery2020 (http:// safesurgery2020.org/). SafeSurgery2020 brings together government, implementers, academics, and advocates to implement and evaluate interventions designed to improve the surgical systems of three countries in Africa and Southeast Asia by 2020.

As surgery seeks to remain a permanent part of the international public health agenda, constant and committed efforts are required from the global surgery community - from all stakeholders - to promote and support advocacy, research, education, and implementation in this growing field. To effectuate real change in the surgical system, public health system experts, surgeons, and implementers must work together to bridge the gap between implementation and research to evaluate programs and develop evidence-based, impactful and cost-effective solutions to global surgery's complex challenge of improving access to quality surgical care for the 5 billion people worldwide who do not have access to it 1 . 


\section{Contributors}

I. Citron and J. G. Meara co-designed, co-wrote, and co-edited the article.
1. Debas HT, Donkor P, Gawande A, Jamison DT, Kruk ME, Mock CN. Disease control priorities. 3rd Ed. Volume 1: essential surgery. Washington DC: World Bank; 2015.

2. Meara JG, Leather AJM, Hagander L, Alkire BC, Alonso N, Ameh EA, et al. Global surgery 2030: evidence and solutions for achieving health, welfare, and economic development. Lancet 2015; 386:569-624.

3. World Health Assembly. Strengthening emergency and essential surgical care as a part of universal health coverage. WHA68.15. Agenda item 17.1. http://apps.who.int/gb/ebwha/ pdf_files/WHA68/A68_R15-en.pdf (accessed on 18/Jul/2017).

4. Scheffer M, Saluja S, Alonso N. Surgical care in the public health agenda. Cad Saúde Pública 2017; 33:e00104717.

5. Ministry of Health, Republic of Zambia. National surgical obstetric and anaesthesia strategic plan 2017-2021. http://docs.wixstatic. com/ugd/d9a674_70f6813fe4e74c4d99eb028 336a38745.pdf (accessed on 18/Jul/2017).

6. Federal Ministry of Health of Ethiopia. National five years safe surgery strategic plan 2016-2020. http://docs.wixstatic.com/ugd/d9 a674_2ee52716f17f4ac4b1152f3b06aec61b. pdf (accessed on 18/Jul/2017).

7. Weiser TG, Haynes A, George M, Lipsitz SR, Esquivel MM, Uribe-Leitz T, et al. Size and distribution of the global volume of surgery in 2012. Bull World Health Organ 2016; 94 : 201-9F. 